\title{
Fracture rates lower in rural than urban communities: the Geelong Osteoporosis Study
}

\author{
K M Sanders, G C Nicholson, A M Ugoni, E Seeman, J A Pasco, M A Kotowicz
}

J Epidemiol Community Health 2002;56:466-470

\begin{abstract}
See end of article for authors' affiliations

Correspondence to

Dr G C Nicholson, The

University of Melbourne,

Department of Clinical and

Biomedical Science,

Barwon Health-Geelong

Hospital, PO Box 281,

Geelong 3220, Australia:

gcn@unimelb.edu.au
\end{abstract}

Accepted for publication 25 October 2001

\begin{abstract}
Background: Urban and rural communities differ in the incidence of several diseases including coronary heart disease and some cancers. Lower hip fracture rates among rural than urban populations have been reported but few studies have compared rural and urban fractures at sites other than the hip.

Objective: To compare total and site specific fracture rates among adult residents of rural and urban communities within the same population.

Design and setting: This is a population based study on osteoporosis in Australia. All fractures occurring in adult residents over a two year period were ascertained using radiological reports. The rural and urban areas are in close proximity, with the same medical, hospital, and radiological facilities permitting uniform fracture ascertainment.

Main outcome measures: All fracture rates were age adjusted and sex adjusted to the Australian population according to the 1996 census of the Australian Bureau of Statistics and described as the rate per 10000 person years. The $p$ values refer to the adjusted rate difference.

Results: The hip fracture rate (incidence per 10000 person years) was $32 \%$ lower (39 v 57, $p<0.001)$, and the total fracture rate $15 \%$ lower $(160 \vee 188, p=0.004)$ among rural than urban residents, respectively. The lower fracture rates in the rural population were also apparent for pelvic fractures.

Conclusion: In the older rural population, lower fracture rates at sites typically associated with osteoporosis suggest environmental factors may have a different impact on bone health in this community. If the national rate of hip fracture could be reduced to that of the rural population, the projected increase in hip fracture number attributable to aging of the population could be prevented.
\end{abstract}

$\mathrm{R}$ ural and urban communities differ in the incidence of several diseases including coronary heart disease ${ }^{1}$ and some cancers. $^{23}$ Differences in rural and urban hip fracture rates have been reported between communities in Scandinavia and North America, with most ${ }^{4-8}$ but not all studies ${ }^{910}$ reporting lower rates of hip fracture in rural communities. Increasing hip fracture rates in Hong Kong and other parts of Asia have been attributed to increasing urbanisation. ${ }^{11}$

While hip fracture is viewed as the most serious consequence of osteoporosis, a fracture at any site is associated with a 1.5-fold increased risk of hip fracture. ${ }^{12}$ Non-hip fractures account for $80 \%$ of fractures in the population aged 35 years and over, and $71 \%$ in those aged 60 years and over. ${ }^{13}$ Few studies $^{10}{ }^{14}$ have compared rural and urban fractures at sites other than the hip. It is unclear if rural fracture rates are lower at all sites, in all age groups and in both men and women.

The Geelong Osteoporosis Study is a population based project in which age specific, sex specific, and site specific fracture rates were determined within a well characterised region, the Barwon Statistical Division. ${ }^{15}$ The division comprises both urban and rural localities that are in close proximity and are serviced by the same centralised medical and radiological services. We are able, using identical methodology, to concurrently ascertain all incident fractures occurring in the rural and urban communities and, thereby, test the hypothesis that fracture rates are lower in rural communities.

\section{METHODS}

\section{Urban and rural population}

The study region, defined by the Australian Bureau of Statistics (ABS) as the Barwon Statistical Division, has a population of 221000 . Using the 1996 census, the ABS provided age specific and sex specific population figures by postcode. A publi- cation by the Geelong Economic Development Unit ${ }^{16}$ independently classified the region's suburbs and towns as rural or urban. A list of the region's postcodes was then allocated to the urban or rural category according to this classification of the region's suburbs and towns. The region's major city, Geelong and its immediate suburbs, constituted the urban area and is the third largest non-capital city in Australia. The study region's rural population includes coastal resort towns, smaller "hobby" farms as well as many traditional farming communities supported by small townships with a strong agricultural base.

\section{Fracture ascertainment}

Using radiological reports from the two medical imaging practices servicing both the urban and rural areas of the study region, all fractures occurring in adults aged 35 years and over, were identified. The two year ascertainment period in both the urban and rural areas was identical and concurrent, from February 1994 to February 1996. This method of fracture ascertainment has been previously described ${ }^{13}$ and validated using hip fracture as a model. ${ }^{17}$ Vertebral fracture rates should be interpreted with caution as these fractures can be asymptomatic and so may be undiagnosed radiologically during the ascertainment period.

\section{Trauma status of the fracture event}

Within the ascertainment period, 1380 women sustained fracture(s) and were invited to participate in our study. As a result, the degree of trauma associated with the fracture event was ascertained by personal interview in 826 women. Spontaneous fractures, fractures resulting from overexertion or strenuous movements, fractures occurring with falls from standing height or less, and "other unspecified" falls such as when the patient was found lying on the floor and was unable 


\begin{tabular}{|c|c|c|c|c|}
\hline Age $(y)$ & & Urban & Rural & $\begin{array}{l}\text { \% Rural in our } \\
\text { study region }\end{array}$ \\
\hline \multicolumn{5}{|c|}{ (A) Study region population: "The Barwon Statistical Division"* } \\
\hline \multirow[t]{2}{*}{$\geqslant 35$} & Women & 35981 & 21404 & 37.3 \\
\hline & Men & 31722 & 20031 & 38.7 \\
\hline \multirow{2}{*}{$\geqslant 60$} & Women & 14081 & 7982 & 36.2 \\
\hline & Men & 10613 & 6755 & 38.9 \\
\hline Age (y) & Study region characteristics & $\begin{array}{l}\text { Urban } \\
\mathrm{n}(\%)\end{array}$ & $\begin{array}{l}\text { Urban } \\
\mathrm{n}(\%)\end{array}$ & $\begin{array}{l}\text { Urban } \\
\mathrm{n}(\%)\end{array}$ \\
\hline \multicolumn{5}{|c|}{ (B) Demographic characteristics of our study region compared with Australia* } \\
\hline$\geqslant 20$ & Persons employed in Agriculture, Forestry and Fishing & $492(1.0)$ & $2677(9.5)$ & $311659(4.4)$ \\
\hline \multirow[t]{2}{*}{$\geqslant 60$} & Men living alone & $1631(6.6)$ & $912(6.2)$ & $191938(6.6)$ \\
\hline & Women living alone & $4827(34.3)$ & $2177(27.3)$ & $471379(29.5)$ \\
\hline $60-64$ & Employment density & $1220(22.2)$ & $848(26.5)$ & $195158(28.3)$ \\
\hline
\end{tabular}

*Data from Australian Bureau of Statistics using the 1996 census. Employment density based on full time employment. Other demographics of the study region are provided in Henry M et al, J Clin Densitometry 2000;3: 261-8. $\mathrm{n}$ refers to the number of people in each category.

to remember how she fell, were classified as low trauma. All other fracture events including falls from one level to another were classified as high trauma.

\section{Rural and urban fracture rates}

The entire population of the study region aged 35 years and over was considered to be at risk. Fracture cases were allocated as urban or rural on the basis of residential postcode as described above. All fracture rates are quoted as incidence per 10000 persons per annum. For comparison of fracture rates both urban and rural fracture incidence were standardised to the age specific and sex specific profile of the 1996 Australian population so that any differences between the rural and urban populations in the five year age profile did not distort the results. The $\mathrm{p}$ value refers to the adjusted rate difference. Rate differences were assessed using the following formulas

$$
\begin{aligned}
=a / N_{1}-b / N_{2} \text { where } & a=\text { fracture cases from "urban" area } \\
& N_{1}=\text { urban population } \\
& b=\text { fracture cases from "rural area" } \\
& N_{2}=\text { rural population }
\end{aligned}
$$

Standard error of the rate difference $s e(R D)=$ square root $\left[a / N_{1}^{2}+b / N_{2}^{2}\right]$. The $z$ score of the rate difference $=/ \mathrm{se}(R D)$ and $z>1.96$ is equivalent to $p<0.05$.

The rate difference between the urban and rural environments was more pronounced when the analysis was restricted to the population aged 60 years and over. Unless otherwise mentioned, the results presented refer to the population aged 60 years and over. The authors' acknowledge the number of significance tests made in this study. As a concession to this, the authors regard significance to be less than 0.01 , and $p$ values in the range 0.01 to 0.05 as "moderate" significance. The $\mathrm{p}$ values have been published to enable the reader to make their own judgement.

\section{Ethics approval}

This study was approved by the Barwon Health Research and Ethics Advisory Committee.

\section{RESULTS \\ Demographics}

Of the region's 109923 residents aged 35 years and over, 38\% of men and $37 \%$ of women resided in the rural areas. The proportion of women residing in rural areas ranged from $40 \%$ among the 35 to 39 year olds, to $33 \%$ among those aged over 90 years. The proportion of rural men was remarkably consistent over the age groups with $41 \%$ among those aged 40 to 44 years old, and $36 \%$ among those aged 80 to 84 years old. A comparison of some demographic characteristics is presented in table 1.

\section{All fractures}

The total fracture rate among rural residents aged 60 years and older was $15 \%$ lower than that among urban residents ( $160 \mathrm{v}$ $188, \mathrm{p}=0.004$ rural $v$ urban) due to lower non-hip as well as hip, fracture rates (table 2A). The fracture rate at sites often associated with osteoporosis (hip, spine, Colles' forearm, humerus and pelvis) tended to be lower in the rural population (tables $2 \mathrm{~A}$ and $\mathrm{B}$ ). When typical osteoporotic sites were grouped without the hip site, (spine, Colles' forearm, humerus and pelvis) the fracture rate was $18 \%$ lower in the rural than urban population (rate: rural $72 v 88, \mathrm{p}=0.007$ rural $v$ urban). However, when fractures at other sites were grouped, the fracture rate tended to be higher in the rural population. The lower leg fracture rate was significantly higher in the rural population (table 3 ).

In the younger group of 35 to 50 years, the incidence of fracture was higher in men than women in both the rural and urban population (fig l). The age group in which the fracture rate in women exceeded the rate in men was 60-64 years in the rural population and 55 to 59 years in the urban population. When the analysis was restricted to those aged 60 years and over, the difference in fracture rate between women and men was greater than the difference between the overall rural and urban populations. The total fracture rate in women was approximately threefold higher than in men (3.2-fold and 2.6 -fold in the rural and urban populations, respectively) yet the overall difference between the rural and urban populations was $15 \%$ (table $2 \mathrm{~A}$ ).

The proportion of fracture events classified as low and high trauma did not vary between women in the rural and urban populations. The trauma status is known in 826 women, $65.6 \%$ $(n=298 / 454)$ of the rural women and $57.0 \%(n=528 / 926)$ of the urban women. There was no age difference between the two groups of participants (mean (SEM); 67.1 (0.8) years $v$ 67.8 (0.6) years, rural: urban, respectively; $\mathrm{p}=0.52$ ). Among those aged less than 50 years, high trauma fractures accounted for $40 \%(n=16 / 40)$ and $46 \%(n=35 / 76)$ in the rural and urban populations, respectively $(\mathrm{p}=0.53)$. Among these women aged 50 years and over, high trauma fractures accounted for $21 \%(54 / 258)$ and $19 \%(87 / 452)$ in the rural and urban populations, respectively $(\mathrm{p}=0.59)$.

\section{Hip fractures}

Fractures at the hip displayed the highest site specific rate difference between the rural and urban populations (table $2 \mathrm{~A}$ ). The age adjusted incidence of hip fracture was 32\% lower among rural than urban residents aged 60 years and over (rural $v$ urban, per 10000 person years; $39 v 57, \mathrm{p}<0.001$ ). The mean age of hip fracture was lower in men than women and did not differ between the rural and urban populations (men, rural 76.9 (2.3) years $v$ urban 77.8 (1.3) years, $\mathrm{p}=0.75$; women, 
Table 2

\begin{tabular}{|c|c|c|c|c|c|c|c|c|c|}
\hline \multirow[b]{2}{*}{ Fracture site } & \multicolumn{3}{|l|}{ Women } & \multicolumn{3}{|l|}{ Men } & \multicolumn{3}{|l|}{ Both sexes } \\
\hline & Urban & Rural & $\mathrm{p}$ Value & Urban & Rural & $\mathrm{p}$ Value & Urban & Rural & $\mathrm{p}$ Value \\
\hline \multicolumn{10}{|c|}{ (A) Persons aged 60 years and over. Age-adjusted fracture rates per 10000 person years } \\
\hline Hip & $78(226)$ & $58(89)$ & 0.01 & $30(70)$ & $18(25)$ & 0.02 & $57(51$ to 64$)$ & 39 (33 to 47$)$ & $<0.001$ \\
\hline Spine & 50 (144) & 48 (77) & 0.76 & $17(36)$ & 13 (18) & 0.37 & 36 (31 to 42$)$ & 32 (26 to 39 ) & 0.37 \\
\hline Colles & 40 (1 14) & $32(51)$ & 0.2 & $3(7)$ & $4(6)$ & 0.62 & $24(20$ to 29$)$ & 19 (15 to 25$)$ & 0.17 \\
\hline Humerus & $25(72)$ & 25 (39) & 0.90 & $6(14)$ & $3(5)$ & 0.23 & 17 (14 to 21$)$ & $15(11$ to 20$)$ & 0.49 \\
\hline Pelvis & $15(43)$ & $7(11)$ & 0.01 & $6(13)$ & $3(4)$ & 0.2 & $11(9$ to 14$)$ & $5(3$ to 8$)$ & 0.004 \\
\hline grouped* $^{*}$ & $130(373)$ & $112(178)$ & 0.05 & $32(70)$ & 24 (33) & 0.14 & 88 (82 to 99) & 72 (63 to 82$)$ & 0.02 \\
\hline Other sites grouped $\dagger$ & 60 (169) & $64(102)$ & 0.62 & $39(82)$ & $46(62)$ & 0.32 & $51(45$ to 58$)$ & $56(48$ to 65$)$ & 0.37 \\
\hline All sites grouped & $255(731)$ & $223(352)$ & 0.046 & $99(221)$ & $84(118)$ & 0.15 & 188 (176 to 200 ) & $160(146$ to 175$)$ & 0.004 \\
\hline \multicolumn{10}{|c|}{ (B) Persons aged 35 years and over. Age adjusted fracture rates per 10000 person years } \\
\hline Hip & $28(229)$ & $21(92)$ & 0.02 & $11(79)$ & $6(28)$ & 0.01 & $20(18$ to 22$)$ & $14(12$ to 17$)$ & 0.001 \\
\hline Spine & $20(163)$ & $18(80)$ & 0.30 & $7(45)$ & $7(30)$ & 0.73 & $14(12$ to 16$)$ & $13(11$ to 16$)$ & 0.40 \\
\hline Colles & $19(146)$ & $15(66)$ & 0.14 & $4(25)$ & 5 (18) & 0.67 & $12(10$ to 14$)$ & $10(8$ to 13$)$ & 0.21 \\
\hline Humerus & $11(84)$ & $10(44)$ & 0.76 & $4(26)$ & $2(7)$ & 0.02 & $7(6$ to 9$)$ & $6(5$ to 8$)$ & 0.19 \\
\hline Pelvis & $6(48)$ & $3(15)$ & 0.05 & $2(17)$ & 2 (7) & 0.44 & $4(3$ to 5$)$ & 3 (2 to 5$)$ & 0.03 \\
\hline grouped $^{*}$ & $56(441)$ & $46(205)$ & 0.004 & 17 (113) & $15(62)$ & 0.24 & 37 (34 to 41$)$ & 31 (27 to 36$)$ & 0.10 \\
\hline Other sites grouped $\dagger$ & $40(299)$ & $40(173)$ & 0.94 & $51(322)$ & 52 (207) & 0.78 & $45(40$ to 51$)$ & $46(40$ to 54$)$ & 0.77 \\
\hline All sites grouped & $118(926)$ & $103(454)$ & 0.02 & 78 (509) & 73 (295) & 0.40 & $99(93$ to 106$)$ & 89 (81 to 97$)$ & 0.01 \\
\hline
\end{tabular}

Actual number of fractures shown in parentheses except for columns referring to both sexes, where the parentheses refer to the $95 \%$ confidence intervals. The total of "all sites" is less than the number of fractures at each site as people who sustain fractures at multiple sites have been counted only once in the "all sites" number of people who sustained fracture(s). *Figures refer to fractures at the spine, Colles, humerus and pelvis grouped together. †Figures refer to fractures at all sites except the hip, spine, Colles, humerus and pelvis, grouped together.

Table 3 Persons aged 60 years and over. Site specific fracture rates per 10000 person years

\begin{tabular}{llll}
\hline & \multicolumn{2}{l}{ Fracture rate } & \\
\cline { 2 - 4 } Fracture site & Urban & Rural & $\begin{array}{c}\text { rate difference } \\
\text { rate }\end{array}$ \\
\cline { 2 - 4 } $\begin{array}{llll}\text { Hip- trochanteric } \\
\text { Hip- cervical }\end{array}$ & $29.5(152)$ & $20.8(60)$ & 0.02 \\
& $27.9(145)$ & $18.6(54)$ & 0.02 \\
Facial & $1.2(6)$ & $1.0(3)$ & 0.47 \\
Skull & 0 & $0.3(1)$ & 0.67 \\
Ribs & $12.2(61)$ & $11.7(34)$ & 0.90 \\
Clavicle & $1.9(10)$ & $2.7(8)$ & 0.21 \\
Scapula & $1.3(7)$ & $1.0(3)$ & 0.42 \\
Wrist- carpal & $1.6(8)$ & $1.7(5)$ & 0.85 \\
Hand & $2.3(11)$ & $2.4(7)$ & 0.94 \\
Finger & $3.3(16)$ & $4.5(13)$ & 0.45 \\
Upper leg & $3.5(18)$ & $1.4(4)$ & 0.02 \\
Patella & $3.0(15)$ & $2.7(8)$ & 0.90 \\
Tibia and fibula & $6.2(31)$ & $10.2(30)$ & 0.04 \\
Ankle & $7.3(36)$ & $6.6(19)$ & 0.65 \\
Foot & $3.8(18)$ & $4.1(12)$ & 0.80 \\
\hline
\end{tabular}

Actual number of fractures shown in parentheses. Rates are age and sex adjusted. The $p$ value refers to the rate difference. Note: one women sustained both a trochanteric and cervical hip fracture but was counted once in the total number of hip fractures in table 2 .

rural 81.7 ( 1.1 ) years $v$ urban $82.5(0.5)$ years, $\mathrm{p}=0.51)$. The ratio of hip fracture(s) in women to men was 3.6 and 3.2 for the rural and urban populations, respectively. Among men, the hip fracture rate was $40 \%$ lower in the rural population whereas the rate among rural women was $26 \%$ lower than their urban counterparts. The rate of trochanteric fractures did not differ from the cervical hip fracture rate in either the urban or rural population (rate difference; urban: men $p=0.2$, women $\mathrm{p}=0.3$; rural: men $\mathrm{p}=0.6$, women $\mathrm{p}=0.8$ ) (table 3$)$. In the rural population, hip fractures accounted for only $21 \%$ $(n=25 / 118)$ and $25 \%(n=89 / 352)$ of all fractures in men and women, respectively, compared with $32 \%(n=70 / 221)$ and $31 \%(n=226 / 731)$ of all fractures in the urban men and women, respectively.

\section{DISCUSSION}

We report that the total fracture rate, adjusted for age and sex, was $15 \%$ lower in the rural than the urban population. The lower fracture rates in the rural population were also apparent for pelvic fractures. The rural fracture rate was $32 \%$ lower than the urban for hip fractures, $45 \%$ lower for pelvic fractures and $18 \%$ lower when spinal, Colles, humeral and pelvic fractures were grouped. In contrast, when other less common sites of fracture were grouped, the rural fracture rate was $10 \%$ higher than that in the urban population.

This trend of lower rural fracture rates at sites associated with osteoporosis has not been previously reported although few studies have compared rural and urban fracture rates at sites other than the hip. Melton et al reported fracture rates were $13 \%$ lower in the surrounding Olmstead County compared with urban Rochester but site specific differences were not statistically significant. ${ }^{10}$ Jonsson et al reported a lower prevalence of self reported fractures in the rural elderly compared with urban dwellers, ${ }^{14}$ however site specific fracture rates could not determined.

Our finding of a $32 \%$ lower hip fracture rate among rural residents is consistent with that of other studies. Differences of 1.2-fold to 1.6-fold have been reported between rural and urban populations in northern and central Norway, western Sweden, and the Olmstead County in North America. ${ }^{5-8} 141819$ It has been suggested that higher rates of physical activity in agricultural occupations contribute to differences in rural and urban hip fracture rates. ${ }^{74} 19$ If true in our setting, this is consistent with a greater difference in hip fracture rates in men than in women as the rate of hip fracture in our region was $40 \%$ lower in rural than urban men compared with an $18 \%$ lower rate in rural than urban women. Although hip fractures are uncommon in those aged less than 60 years, such differences in physical activity may have been more apparent 30 to 50 years ago and contribute to lower rural/urban difference when all adults aged 35 years and over, are included in the analysis (table 2A and B). Secular increases in hip fracture rates have been reported in the United Kingdom and elsewhere. ${ }^{19-21}$ Factors contributing to this increase could be more apparent in the urban communities with a time lag before these changes are observed in rural communities. Repeat fracture ascertainment in the same study region may confirm this hypothesis.

In this study, gender differences influenced fracture risk to a greater extent than rural/urban differences (fig 1). We found that the gender related differences in hip fracture rates were 


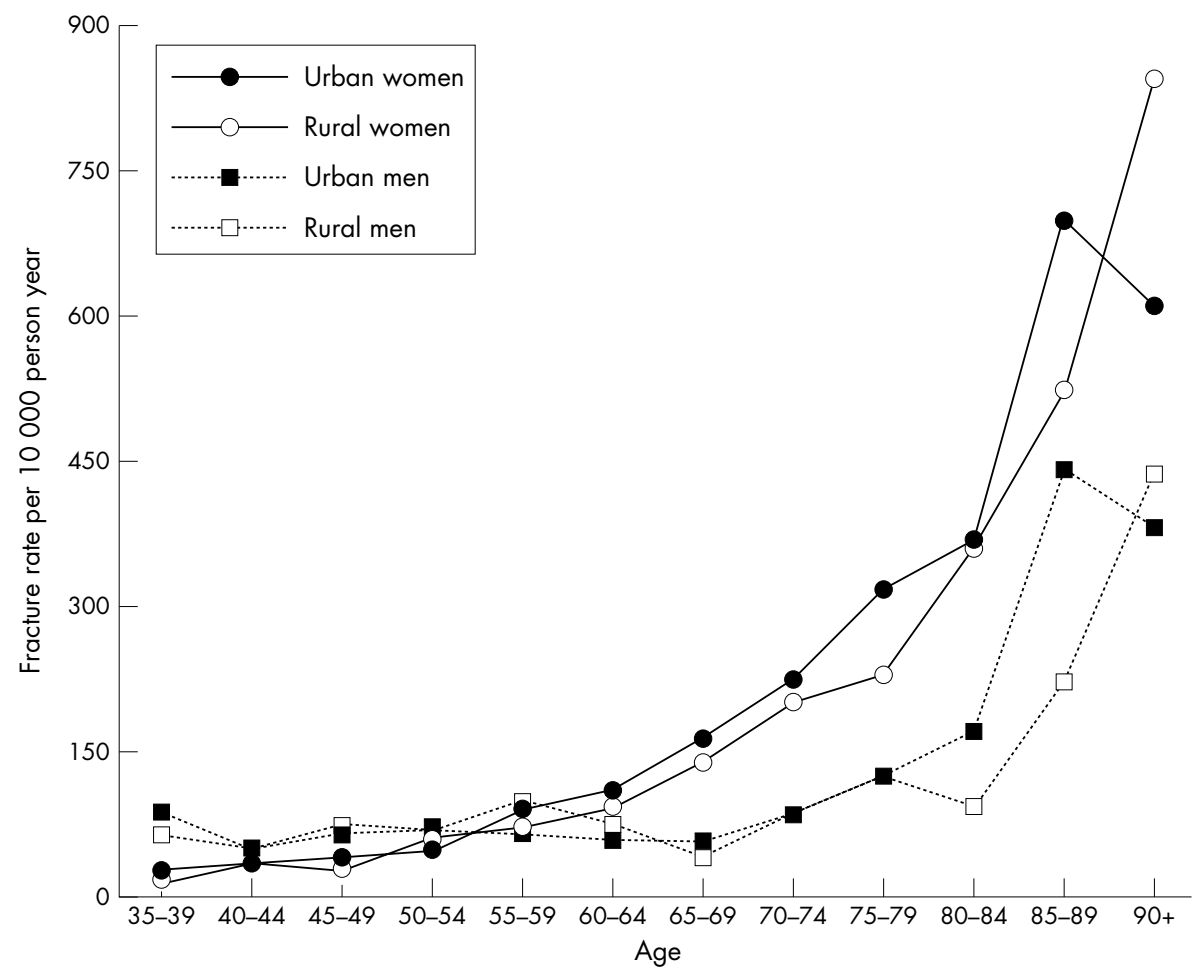

Figure 1 Rural and urban fracture rates at all sites combined. Rates are age standardised and sex standardised to the 1996 Australian population and expressed as rate per 10000 persons per annum.

almost double the rural/urban difference. In both populations, the hip fracture rate in women was approximately threefold higher than the rate in men compared with a 1.5 -fold difference between the urban and rural populations. Although this differs from findings in the MEDOS study ${ }^{22}$ where gender differences were less than regional differences, there were greater similarities between our urban and rural regions than those included in the MEDOS study. Our regions are in close proximity, share the same hospital and medical facilities, and have no apparent differences in ethnicity. We report lower fracture rates in the rural population despite the many similarities between our rural and urban sectors and the inclusion of coastal resort towns in our rural population. In women in whom we had these data, the proportion of fractures resulting from high trauma did not differ between rural and urban groups. Nevertheless, it would be interesting to analyse the trauma classification in men as a higher physical activity level in a rural environment may lead to a higher proportion of high trauma fractures. This would have the effect of minimising a lower rural fracture rate.

We were unable to adjust the analysis for length of residence in a rural or urban environment. A greater sensitivity to detect higher rates of fracture among urban dwellers has been reported when the analysis was restricted to urban or rural dwellers who had been raised and still living in the city (urban) or countryside (rural). ${ }^{14}{ }^{23}$ It is possible that the more frail elderly in the rural environment move to the urban region as their health and independence declines. In our study region, the proportion of the population who reside in the rural region does not change dramatically between 35 year old and $90+$ year olds. The proportion of women in the rural region decreases $6.5 \%$ over this age span, whereas the percentage of men decreases by only $2 \%$ yet the greater difference in hip fracture rates occurs in men.

Social dependency and early retirement have been associated with an increased risk of trochanteric fractures in urban men. ${ }^{14}$ Among our urban dwellers, a higher percentage of residents lived alone or were in early retirement (table 1). However, the ratio of trochanteric to cervical hip fractures did not vary between urban and rural men or women, and rates of both fractures were higher in the urban population.

\section{Key points}

- Urban and rural communities differ in their incidence of several diseases. We report a $15 \%$ lower rate of fracture in our rural population.

- Lower rural fracture rates are principally observed at the hip $(32 \%)$ and pelvis $(45 \%)$.

- Fracture rates at sites not typically associated with osteoporosis did not differ between the rural and urban communities.

- Our fracture ascertainment was identical and concurrent between our rural and urban areas. The same medical imaging practices provide services to both populations.

- If urban populations could reduce their hip fracture rate to that of the rural region, the expected increase in hip fracture could be averted.

Although substantial differences in rates can be associated with differences in fracture ascertainment and inaccuracies in determining the elderly population, ${ }^{24}$ we do not consider that this error would account for our regional differences. The determination of the urban and rural population and the ascertainment of fractures were identical and concurrent between our communities. Our urban hip fracture rate did not differ from that ascertained during the same period in an urban region of our nearest capital city $(57 v 62 ; \mathrm{p}=0.1$, urban Geelong $v$ Northern Corridor of Melbourne, respectively: unpublished results).

This study confirms lower rates of hip fracture among rural dwellers. Furthermore, the analyses suggest this pattern is applicable to other fractures commonly associated with osteoporosis. Lower rural fracture rates at sites typically associated with osteoporosis, suggest a rural environment reduces fracture risk in the elderly. It is unclear from this study if the lower risk directly relates to bone health or to the risk of falls in the elderly population. If the national rate of hip fracture could be reduced to that of the rural population, the annual number of adults sustaining hip fractures would remain stable 
despite the aging of the Australian population. In the population aged 35 years and over, an incidence of 13 per 10000 person years would stabilise hip fracture numbers by the year $2016 .{ }^{26}$ The development of strategies to reduce any additional risk of fracture imposed by living in an urban environment therefore has the potential to significantly decrease the social and economic burden of osteoporosis.

\section{ACKNOWLEDGEMENTS}

Dr K Sanders is a recipient of an International Osteoporosis Foundation Claus Christiansen Research Fellowship.

\section{Authors' affiliations}

K M Sanders, G C Nicholson, J A Pasco, M A Kotowicz, The University of Melbourne, Department of Clinical and Biomedical Sciences, Barwon Health, Geelong, Australia

A M Ugoni, The University of Melbourne, Department of General Practice and Public Health, Carlton, Australia

E Seeman, The University of Melbourne, Department of Endrocrinology, Austin and Repatriation Medical Centre, Heidelberg, Australia

Funding: The Geelong Osteoporosis Study is supported by a grant from The Victorian Health Promotion Foundation.

Conflicts of interest: none.

\section{REFERENCES}

1 Sexton P, Sexton T. Excess coronary mortality among Australian men and women living outside the capital statistical divisions. Med J Aust 2000; 172:370-4.

2 Schootman M, Fuortes L. Breast and cervical carcinoma: the correlation of activity limitations and rurality with screening, disease incidence, and mortality. Cancer 1999;86:1087-94.

3 Howe $\mathbf{H}$, Johnson T, Lehnherr $M$, et al. Patterns of breast cancer treatment: a comparison of a rural population with an urban population and a community clinical oncology program sample. Cancer Control 1995; 2:113-20.

4 Norton R, Yee T, Rodgers A, et al. Regional variation in the incidence of hip fracture in New Zealand. N Z Med J 1997; 1 10:78-80

5 Madhok R, Melton LI, Atkinson EJ, et al. Urban vs rural increase in hip fracture incidence. Age and sex of 901 cases 1980-89 in Olmsted County, USA. Acta Orthop Scand 1993:64:543-8.

6 Falch JA, Kaastad TS, Bohler G, et al. Secular increase and geographical differences in hip fracture incidence in Norway. Bone $1993 ; 14: 643-5$
7 Mannius S, Mellstrom D, Oden A, et al. Incidence of hip fracture in Western Sweden 1974-1982. Comparison of rural and urban populations. Acta Ortho Scand 1987;58:38-42.

8 Kaastad TS, Meyer HE, Falch JA. Incidence of hip fracture in Oslo, Norway: Differences within the city. Bone 1998;22:175-8.

9 Jacobsen SJ, Goldberg J, Miles TP, et al. Regional variation in the incidence of hip fracture. US white women aged 65 years and older. JAMA 1990;264:500-2.

10 Melton LI, Crowson C, O'Fallon W. Fracture incidence in Olmsted County, Minnesota: comparison of urban with rural rates over time. Osteoporos Int 1999:9:29-37.

11 Lau EMC. The epidemiology of hip fracture in Asia: an update. Osteoporos Int 1996;6 (suppl 3):s19-23.

12 Cummings SR, Nevitt MC, Browner WS, et al. Risk factors for hip fractures in white women. N Engl J Med 1995;332:767-73.

13 Sanders K, Seeman E, Ugoni A, et al. Age- and gender-specific rate of fractures in Australia: a population based study. Osteoporos Int 1999;10:240-7

14 Jonsson B, Gardsell P, Johnell O, et al. Differences in fracture pattern between an urban and a rural population: a comparative population-based study in southern Sweden. Osteoporos Int 1992;2:269-73.

15 Australian Bureau of Statistics. Statistical Geography. Catalogue no 1103.2:1995.

16 Geelong EDU. Geelong: Victoria, Australia - facts at a glance. City of Greater Geelong, PO Box 104, Geelong 3220

17 Pasco J, Henry M, Gaudry T, et al. Identification of incident fractures: the Geelong Osteoporosis Study. Aust N Z J Med 1999;29:203-6.

18 Sernbo I, Johnell O, Andersson T. Differences in the incidence of hip fracture. Comparison of an urban and rural population in southern Sweden. Acta Ortho Scand 1988;59:382-6.

19 Finsen V, Benum P. Changing incidence of hip fractures in rural and urban areas of central Norway. Clin Orthop Rel Res 1987;218:104-10.

20 Donaldson LJ, Cook A, Thomson RG. Incidence of fractures in a geographically defined population. J Epidemiol Community Health 1990;44:241-5.

21 Baker $M$. An investigation into secular trends in the incidence of femoral neck fractures using hospital activity analysis. J Public Health 1980:94:368-74.

22 Elffors I, Allander E, Kanis JA, et al. The variable incidence of hip fracture in Southern Europe: The MEDOS study. Osteoporos Int 1994:4:253-63.

23 Gardsell $\mathbf{P}$, Johnell $O$, Nilsson BE, et al. Bone mass in an urban and a rural population - a comparative, population-based study in southern Sweden. J Bone Min Res 1991;6:67-75.

24 Bacon W, Maggi S, Looker A, et al. International comparison of hip fracture rates in 1988-89. Osteoporos Int 1996;6:69-75.

25 Maggi S, Kelsey JL, Litvak J, et al. Incidence of hip fractures in the elderly: a cross national analysis. Osteoporos Int 1991;1:232-41.

26 Sanders K, Nicholson G, Ugoni A, et al. Health burden of hip and other fractures in Australia beyond 2000: Projections based on the Geelong Osteoporosis Study. Med J Aust 1999;170:467-70. 